\title{
Experimental research about gaseous emissions coming from multi-floor parks: a real case in Taormina (Italy)
}

\author{
F. Patania, A. Gagliano, F. Nocera, A. Galesi \& A. D’Amico \\ Energy and Environment Division of D.I.I.M., \\ Engineering Faculty of University of Catania, Italy
}

\begin{abstract}
The piling up of many cars in restricted areas could produce dangerous effects on the health of inhabitants of surrounding quarters of a city, especially if there is a very big concentration of vehicles in the area as happens in multi-floor car parks. To test the degree of risk and the way for its control, people carried out an applied research in Taormina city, having as a target two multi-floor car parks: the "Lumbi", about 400m from the city centre and "Catania Gate", very close to the southern part of the city centre. Previously, people carried out an aimed survey on vehicular traffic both going to and coming from the parks, as well as on the stop-times of the cars inside. Subsequently, research proceeded by application of a steady state Gaussian plume model ISC3 (Industrial Source Complex), able to operate both in "short terms" and "long terms", under the hypothesis to consider the whole volume of each parking as a complex source of exhausts. Finally, people carried out a campaign of measurements of concentration of tracer gas in suitable zones of the investigated area. The aim of the paper is to show results pointed out by comparison between forecasted data and those ones measured drawing out peculiar situations in the case of the application of computer code:

- the trend of pollutant concentrations of tracer gas in inhabited area located between the two investigate parks

- the status of air pollution with reference to the limit of Italian environmental legislation

- $\quad$ some possible remedies to try to reduce the pollutant concentrations in the case of overcoming of alarm limits.
\end{abstract}

Keywords: Gaussian model, air pollution, car parking, exhaust gases. 


\section{Object of survey}

The objects of the survey have been two multi-floor car parks, called respectively "Lumbi" and "Porta Catania", located in an inhabited centre of Taormina (Italy), with the aim to investigate the environmental situation of pollution caused by vehicle's exhausts coming from the two car parks. Urban areas interested by the presence of the car parks is characterized by high car traffic and car parks taking up more than $6000 \mathrm{~m}^{2}$ of $13160000 \mathrm{~m}^{2}$ of the pertinent urban area.

\section{Methodology of research}

The research has been carried out in accordance with following steps:

- data acquisition and analysis about daily total number and average per hour of vehicles that use both car parks in holiday days;

- analysis of meteor-climatic historical data of situ;

- choice of dispersion model, that is the 3D ISC3, to forecast concentration of polluting gasses and its patterns running the time;

- $\quad$ choice of computer program to calculate the level of emission coming from vehicles using car parks, that is the COPERT computer program;

- campaign of measurements of PM concentrations, user as tracer pollutant, to test validity of data forecasted by ISC3 by comparison between some forecasted data and that ones measured in the same places of forecasting;

- analysis of results coming from forecasting of dispersion model to estimate both the feasibility of model and the environmental compatibility of pollution coming from parks bringing in this way the research to a conclusion.

\section{The emissions of exhausts}

To estimate the amount of polluting gasses produced inside parks people adopted the "Computer Programme to calculate Emission from Road Transport" (COPERT III). The programme bases calculus on "emission factor approach" and values the emissions of each category of vehicle by "emission curves speed dependent". The calculus is based on the knowledge of parameters such as:

- Composition of circulating fleet of vehicles through the investigated areas in function both of kind of feeding (petrol, diesel oil, GPL) and regulation of reference (conventional or euro). In this case people used data given by ACI (Automobile Club of Italy), fig. 1, fig.2.

- $\quad$ The global emissions of circulating fleet, table 1, fig. 3, fig. 4.

- The cycle of drive in percentage of kind of run (urban, outside the town, motorway, etc.) and the mean velocity for each cycle of drive. In our case people adopted a value of $5,00 \mathrm{~km} / \mathrm{h}$ as velocity of cars inside parks.

- Year's run for each class of vehicle (total $\mathrm{km} / \mathrm{year} \cdot \mathrm{vehicle}$ ).

- Some other parameters such as features of fuels, climatic conditions and so on. 


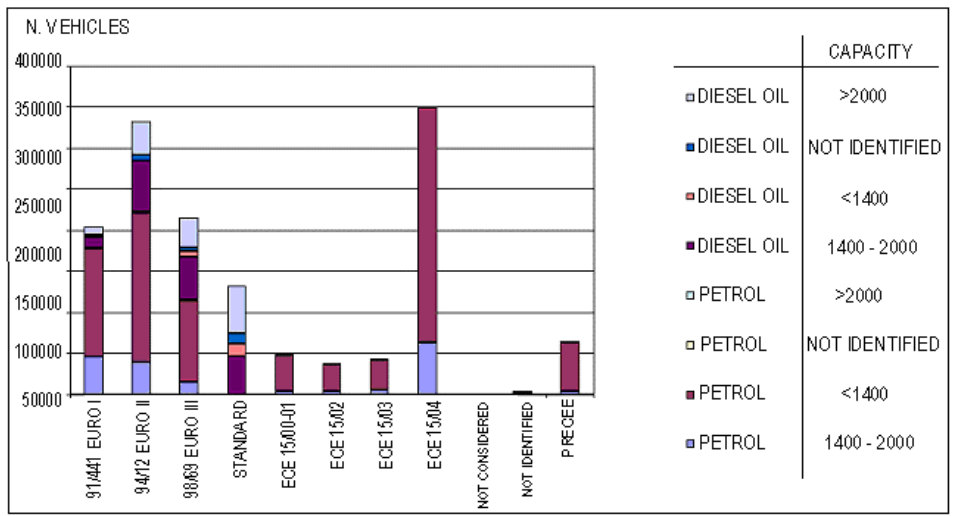

Figure 1: Classes of circulating cars.

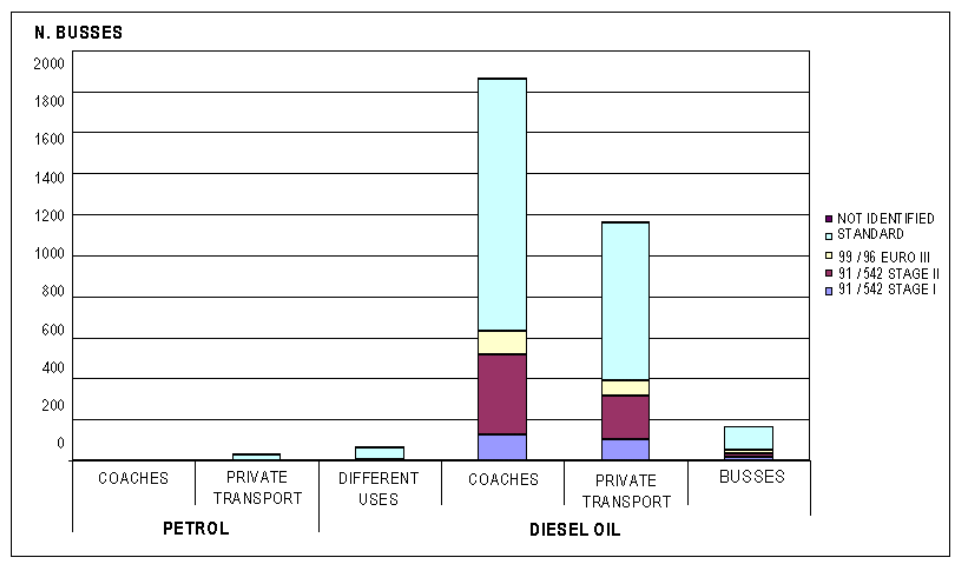

Figure 2: Classes of circulating buses.

Table 1: Global emission of circulating fleet.

\begin{tabular}{|c|c|c|c|c|c|c|}
\cline { 3 - 7 } \multicolumn{2}{c|}{} & \multicolumn{6}{c|}{ Total Emissions (Ton) } \\
\hline Type & Capacity & N. Vehicles & CO & NOX & VOC & PM10 \\
\hline Petrol cars & $<1,41$ & 869124 & 180684,7805 & 2391,78848 & 15967,231 & 0 \\
\hline Petrol cars & $1,4-2,01$ & 180584 & 35436,49951 & 468,289545 & 3107,4911 & 0 \\
\hline Petrol cars & $>2,01$ & 7472 & 1467,944756 & 22,4246435 & 124,7361 & 0 \\
\hline Diesel cars & $<2,01$ & 197480 & 902,2798653 & 521,504744 & 340,73137 & 144,9107 \\
\hline Diesel cars & $>2,01$ & 146141 & 782,8079271 & 499,594452 & 319,69203 & 129,8562 \\
\hline Bus & & 168 & 95,62156057 & 210,356098 & 47,785716 & 12,61593 \\
\hline Coaches & & 1959 & 116,9005151 & 296,026714 & 72,949084 & 18,46777 \\
\hline
\end{tabular}




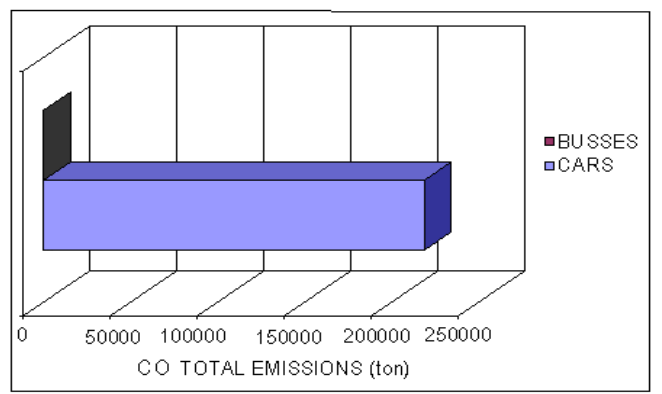

Figure 3: $\quad$ CO total emissions.

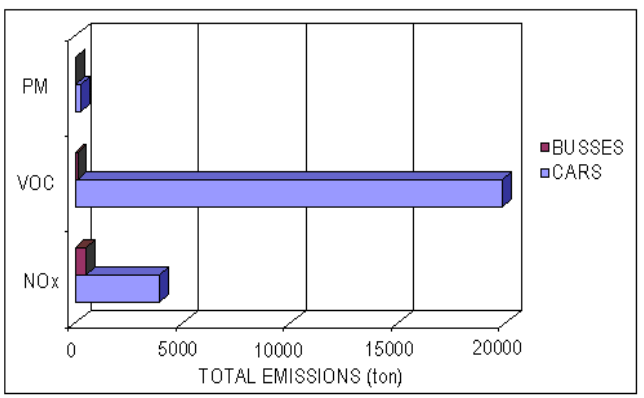

Figure 4: PM, NOX and VOC total emissions.

COPERT programme generates as intermediate results both the "emission factor" referred to each pollutant $(\mathrm{g} / \mathrm{km})$ for each kind of vehicle and the pollutant weigh (tons) that each kind of vehicle gives out during the investigated year. COPERT programme marks more over two kinds of work of an engine, that is "hot working" during the run and "cold working" during the start of run and for each of two gives the formulas to calculate emissions. In our case it has been necessary to calculate "emission factor" in "main weighted mode" to take in account of the real contribution that each category of vehicles gives for each polluting substance of investigation in the parks. In this way people took into account the maximum flux of vehicles per hour which, in comparison with emission factor of each kind of polluting gas, takes to "main weighted emission factor" for each car parks, table 2.

The number of vehicles for each park is taken from data registered in inlet and outlet from parks, table 3.

Table 2: Weighted emission factor.

\begin{tabular}{|c|c|c|c|c|}
\hline \multicolumn{5}{|c|}{ Emission Factor $\mathbf{g} / \mathbf{K m}^{*}$ vehicles } \\
\hline Park & CO & $\mathbf{P M}_{\mathbf{1 0}}$ & NOx & VOC \\
\hline Lumbi & 21.31 & 1.66 & 4.67 & 4.49 \\
\hline Porta Catania & 18.72 & 1.59 & 2.08 & 3.59 \\
\hline
\end{tabular}


Table 3: $\quad$ Total and average per hour number of vehicles.

\begin{tabular}{|c|c|c|c|}
\hline \multirow{2}{*}{ Season } & Park name & \multicolumn{2}{|c|}{ Holidays day 16/08/2004 } \\
\hline \multirow{3}{*}{ August } & \multirow{3}{*}{ Lumbi } & Total & Average per hour \\
\cline { 2 - 4 } & Porta Catania & 5072 & 212 \\
\cline { 2 - 4 } & Put & 182 \\
\hline
\end{tabular}

\section{Dispersion of pollutants}

To have the forecast of trend of polluting concentrations running the time, people adopted the Gaussian model dispersion called Industrial Source Complex version 3 (ISC3) that has been built as follows. The calculus domain is a rectangular area of 2,10m x 2,20m, represented as a Cartesian grid with steps of 10,00m along both $x$ and $y$ axes for the first polluting source (Lumbi park) whilst in the case of second source (Porta Catania) the dimensions of rectangular area are $180,00 \mathrm{~m} \mathrm{x}$ $170,00 \mathrm{~m}$. People chose two kinds of sources, that is "areal source" in the first computation and "volumetric source" in the second computation to refine and improve the results. People took into account the mean meteor-climatic data and mean dispersive characteristics to aim to define the "standard day" for "the temporal scale". In our research the adopted data came from the registration of meteor-climatic steady station of Taormina and are that ones referred to in year 2004, table 4. Particular analysis and statistical elaboration about meteor-climatic features have been made to build five "standard day" to apply to ISC3 model.

Table 4: $\quad$ Meteorological data.

\begin{tabular}{|c|c|c|c|}
\hline Time (h) & Wind direction & $\mathbf{V ~ ( m / s )}$ & $\mathbf{T}(\mathbf{K})$ \\
\hline 1 & 106 & 0,1 & 287,2 \\
\hline 2 & 286 & 0 & 287 \\
\hline 3 & 282 & 0,2 & 287,4 \\
\hline$\ldots$ & $\ldots$ & $\ldots$ & $\ldots$ \\
\hline 24 & 282 & 0,2 & 288 \\
\hline
\end{tabular}

At the end people calculated "mean weighted emission factor" $\left(\mathrm{g} / \mathrm{s} \cdot \mathrm{m}^{2}\right)$ by dividing the amount of pollutants coming from total vehicles travelling along the surfaces of each park and the surface of parks. In the case of "areal source", ISC3 use following formulas to forecast the trend of polluting concentration both in the case of lee side receptors and receptor inside areal source, eqn. (1).

$$
\chi=\frac{Q_{A} K}{2 \pi u_{s}} \int_{x} \frac{V D}{\sigma_{y} \sigma_{z}}\left(\int_{y} \exp \left[-0.5\left(\frac{y}{\sigma_{y}}\right)^{2}\right] d y\right) d x
$$

where:

- $\mathrm{Q}_{\mathrm{A}}=$ specific emission coming from areal source;

- $\mathrm{K}=$ conversion coefficient $\left(10^{6}\right.$ for $\mathrm{Q}$ in $\mathrm{g} / \mathrm{s}$ and concentrations $(\mu \mathrm{s} / \mathrm{s})$; 
- $\mathrm{V}=$ vertical term, factor to take in account the distribution of Gaussian cloud;

- $\mathrm{D}=$ delay coefficient to take in account of the degree of removal of pollutants;

- $\sigma_{\mathrm{y}}, \sigma_{\mathrm{z}}=$ parameters of lateral and vertical diffusion (m);

- $\mathrm{u}_{\mathrm{s}}=$ wind velocity to the height of emissions $(\mathrm{m} / \mathrm{s})$.

The wind velocity $u_{s}$ in correspondence of the height of source $h_{s}$, has been called in function of wind velocity $u_{\text {ref }}$ measured to a reference height by an exponential function, eqn. (2).

$$
\mathrm{u}_{\mathrm{s}}=\mathrm{u}_{\mathrm{ref}}\left(\frac{\mathrm{h}_{\mathrm{s}}}{\mathrm{z}_{\mathrm{ref}}}\right)^{\mathrm{p}}
$$

where $\mathrm{p}$ depend from wind profile coming from table 5.

Table 5: Default values of $\mathrm{p}$.

\begin{tabular}{|c|c|c|}
\hline Stability & \multicolumn{2}{|c|}{ p } \\
\cline { 2 - 3 } Pasquill -Categories & Rural zone & Urban zone \\
\hline A & 0.07 & 0.15 \\
\hline B & 0.07 & 0.15 \\
\hline C & 0.10 & 0.20 \\
\hline D & 0.15 & 0.25 \\
\hline E & 0.35 & 0.30 \\
\hline F & 0.55 & 0.30 \\
\hline
\end{tabular}

The formula to calculate $\sigma_{\mathrm{y}}$ and $\sigma_{\mathrm{z}}$ are respectively:

$$
\sigma_{\mathrm{y}}=465.11628(\mathrm{x}) \tan (\mathrm{TH})
$$

where:

$$
\mathrm{TH}=0.017453293[\mathrm{c}-\mathrm{d} \ln (\mathrm{x})]
$$

and:

$$
\sigma_{\mathrm{z}}=\mathrm{ax}^{\mathrm{b}}
$$

where:

- $\mathrm{x}=$ lee side distance $(\mathrm{km})$;

- $\quad a$ and $b$ are coefficients function of classes of atmospheric stability (Pasquill Categories) and in function of lee side distance. 
The "vertical term V" of equation (1) takes into account the effect tied to many factor such as height of receptors on the ground, presence of thermal inversion layer and so on. The "Decay coefficient D" takes in account of some physical and chemical processes tied to removal of pollutants and is given by the following equations, eqn.(6):

$$
\mathrm{D}=\exp \left(-\psi \times \frac{\mathrm{x}}{\mathrm{u}_{\mathrm{s}}}\right) \text { if } \psi>0 \quad \mathrm{D}=1 \text { if } \psi=0
$$

where:

- $\psi=$ coefficient of decay $\left(\mathrm{s}^{-1}\right)$;

- $\quad \mathrm{x}=$ lee side distance $(\mathrm{km})$;

- $\mathrm{u}_{\mathrm{s}}=$ wind velocity at the height of release of pollutants $(\mathrm{m} / \mathrm{s})$.

The ISC3 model in the case of "volumetric source" uses a virtual point-form source to model effects produced by volumetric source and the trend of polluting concentrations is given by following algorithm, eqn.(7).

$$
\chi=\frac{Q K V D}{2 \pi u_{s} \sigma_{y} \sigma_{z}} \exp \left[-0.5\left(\frac{y}{\sigma_{y}}\right)^{2}\right]
$$

In the case of "areal source" ISC 3 do not take in account the effect of the complex orography of ground on fluid-dynamic of polluting mass and assumes hypotheses of stationariness of diffusive phenomenon. The height of release of polluting gas has been adopted at $0,50 \mathrm{~m}$.

Figure 5 shows some results of simulation for main values of concentrations in the case of time interval shown in parenthesis.

In the case of volumetric source people adopted the volume of parks as volumetric sources of polluting emissions and gave to programme the following further parameters without any changing of dimensions of domains:

- coordinates of centre of domain (m);

- height of release of polluting gas: $0,50 \mathrm{~m} \ldots . .5 \mathrm{~m}$

- initial both lateral and vertical dimensions $(\mathrm{m})$

- $\quad$ specific emission $(\mathrm{g} / \mathrm{s})$ obtained as: emission factor $(\mathrm{g} / \mathrm{km} \cdot \mathrm{vehicle}) \mathrm{x}$ number of vehicles per hour (vehicle/h) $\mathrm{x}$ main covered inside park $(\mathrm{km}) \times 1 / 3600(\mathrm{~h} / \mathrm{s})$.

In this case the "complex 1 algorithms" of ISC 3 takes in account the complex orography of ground to calculate the fluid-dynamic of polluting gases.

An example of the results of simulations, in the case of "volumetric source", is shown in figure 6. By application of the second case people remark that the biggest polluting concentration is localized on the outside of investigated areas for both parks, in a contrary way as in the case of areal source $(0,5 \mathrm{~m})$ and the plume is carried out according to the direction of dominant wind during the hour of the simulated day. In the case of a big velocity of wind or of inversion, there is on the one hand the transport of pollutants to longer distances and on the other the drop of the axis of plume that produces the consequential increase of polluting concentrations near the ground longer distance from the source. 
640 Urban Transport XII: Urban Transport and the Environment in the 21st Century

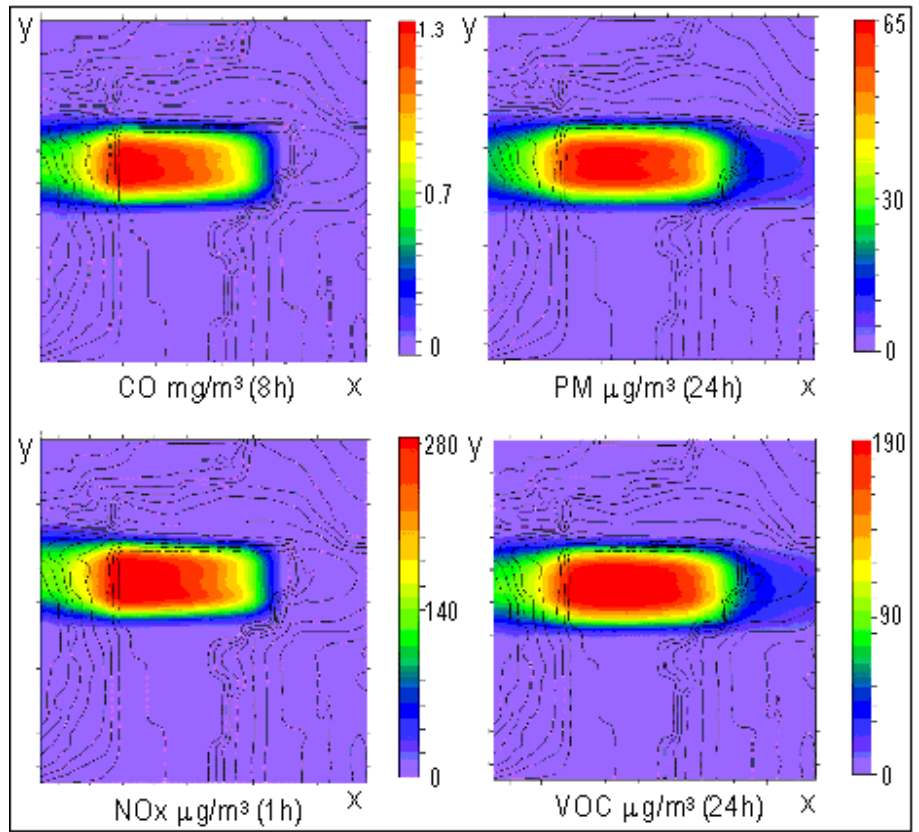

Figure 5: $\quad$ Example of isoconcentration (areal source).

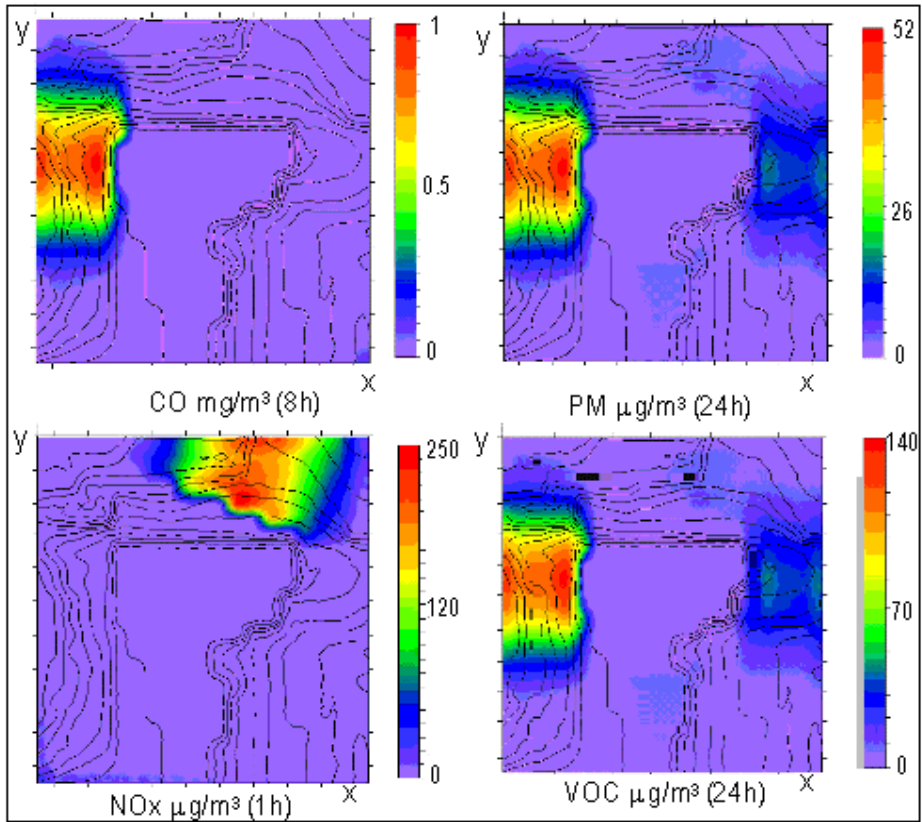

Figure 6: Example of isoconcentration (volumetric source). 


\section{Validation of ISC3}

By results obtained by the campaign of measurements of a tracer pollutant (PM10) done by portable equipment (Enviro Chek Dust Monitor of Grimm) and by means of comparison between measured data and those ones forecasted by the model, people have been able to notice that result of polluting concentration forecasted by "areal source mode" are much lower $(60 \%)$ of measured data whilst in the case of "volumetric source mode" the data forecasted are slightly higher (from 1,5\% to $15 \%$ ) of measured data, table 6 .

In the case of "areal source" people estimate that the considerable difference between forecasted and measured data is originated by some factors such as:

- the distance of places where the measurements have been done has been too big with reference to dimensions of emissive source;

- the average of concentrations are related to $24 \mathrm{~h}$ whilst the period of measurements has been a couple of hours;

- the height of release is not coherent with the real height of receptor.

In the case of "volumetric source" instead the difference between forecasted and measured data is acceptable to our purposes and people think that this difference is originated by some factors such as :

- the calculus of emissions by "factor emission" of COPERT generally gives undervalues data;

- the sources are really not stationary;

- the uncertainty of data airfield: in fact is more complex than the orography of the ground and it is more necessary to have many and significant meteor-climatic stations to define exactly the parameters tied to wind.

Table 6: PM10 concentration.

\begin{tabular}{|c|c|c|c|}
\hline \multirow{2}{*}{ Source } & \multirow{2}{*}{ Park } & \multicolumn{2}{|c|}{$\begin{array}{c}\text { PM10 average daily concentration } \\
\left(\mu \mathbf{g} / \mathbf{m}^{\mathbf{3}}\right)\end{array}$} \\
\cline { 3 - 4 } & & Day 1 & Day 2 \\
\hline \multirow{2}{*}{ Areal } & Porta Catania & 10.72 & 8.054 \\
\cline { 2 - 4 } & Lumbi & 6.787 & 8.522 \\
\hline \multirow{2}{*}{ Volumetric } & Porta Catania & 30.2354 & 25.215 \\
\cline { 2 - 4 } & Lumbi & 23.0019 & 26.27 \\
\hline
\end{tabular}

\section{Conclusions}

- The ISC3, in "volumetric source mode", is quite sufficient to forecast the trend of polluting concentrations in the case of numerous polluting sources, whilst the forecasting is very hard to obtain by use of more complex codes. In this way it can be adopted in not very complex orographic situations, when it is not necessary to follow with high accuracy the dynamic of phenomena and when there aren't significant both spatial and temporal unhomogeneity. 
- The comparison between values of concentration forecasted and that ones allowed by legislation, table 7 , shows the real possibility that, in some zones and under certain meteorclimatic conditions, there could be some negative health effects as regard the inhabitants of town. On these grounds, people will carry out some other forecasting concentrations measurements in situ to calibrate the possible techniques of control and mitigations that are impossible to calibrate on the ground of actual results of research.

Table 7: Forecasted values and upper limit by legislation of pollutants concentration.

\begin{tabular}{|c|c|c|}
\hline Pollutant & $\begin{array}{c}\text { Max Value } \\
\text { (D.M. 31/03/2003 n.7) }\end{array}$ & Forecasted Value \\
\hline $\mathrm{CO}\left(\mathrm{mg} / \mathrm{m}^{3}\right)$ & 10 & $0,1 \div 3,4$ \\
\hline $\mathrm{PM} 10\left(\mu \mathrm{g} / \mathrm{m}^{3}\right)$ & 45 & $10 \div 95$ \\
\hline $\mathrm{NOx}\left(\mu \mathrm{g} / \mathrm{m}^{3}\right)$ & 200 & $50 \div 250$ \\
\hline
\end{tabular}

\section{References}

[1] Patania, F., Gagliano, A., Nocera, F., Incompleteness of the urban traffic plan in preliminary studies of environmental impact: the real case of urban canyon, Urban Transport XI , Editors C.A. Brebbia. L.C. Wadhawa, WIT Press (U.K.), pp.417- 428, 2005.

[2] Patania, F., Gagliano, A., Nocera, F., Galesi, A., An applied test to evaluate the use of fluid dynamic code as a predictive key of air pollution from urban road traffic, Urban Transport X , Editors C.A. Brebbia WIT Press (U.K.), pp.711-716, 2004.

[3] Patania, F., Gagliano, A., Nocera, F., Air pollution and urban plan of road traffic: experimental research about situations of environmental health hazard, Urban Transport IX. , WIT Press Southampton (U.K.), pp.253-262, 2003.

[4] Patania, F., Gagliano, A., Nocera, F., Air pollution drop by technique of urban traffic integrated control system in Catania city (Italy), Urban Transport VII, WIT Press, 2001.

[5] ISC3 - User Guide of Industrial Source Complex Model, Office of Air Quality Planning and Standards (OAQPS), US EPA

[6] Steven R. Hanna, Bruce A. Egan, John Purdum, Jen Wagler, Evaluation of the ADMS, AERMOD, and ISC3 dispersion models with the OPTEX, Duke Forest, Kincaid, Indianapolis and Lovett field datasets, International Journal of Environment and Pollution 2001 - Vol. 16, No.1/2/3/4/5/6 pp.301-314

[7] Baldauf, Richard W.; Wiener, Russell W.; Heist, David K, Methodology for siting ambient air monitors at the neighborhood scale, Journal of the Air \& Waste Management Association, 2002 